\title{
RISCO DE INCÊNDIO SAZONAL EM ÁREA DESCAMPADA E DE FLORESTA PARA DIFERENTES CENÁRIOS CLIMÁTICOS NO MUNICÍPIO DE ÁGUAS MORNAS
}

Roberta Raspini Januário ${ }^{1}$ Rosandro Boligon Minuzzi²

Resumo: O objetivo foi avaliar o risco de incêndio sazonal em área descampada e de floresta, para diferentes cenários climáticos. O local de coleta e estudo de dados foi no município de Águas Mornas, estado de Santa Catarina. Os dados horários foram coletados entre julho de 2017 a fevereiro de 2018, abrangendo as estações inverno, primavera e verão. O risco de incêndio foi determinado pelo índice de Setzer e Fórmula de Monte Alegre. Observou-se a propensão de queimadas em relação aos cenários futuros, justamente pelo aumento da temperatura. $A$ área descampada apresentou maior ocorrência de incêndio em relação a floresta. Nos cenários climáticos há um aumento no risco 'médio', 'alto' e 'muito alto ou crítico' e uma redução no risco 'nulo ou mínimo' e 'pequeno ou baixo'.

Palavras-chave: Incêndio florestal. Índice de Setzer. Fórmula de Monte Alegre.

\section{SEASONAL FIRE RISK IN THE UNFIELDED AREA AND FOREST FOR DIFFERENT CLIMATIC SCENARIOS IN THE ÁGUAS MORNAS CITY}

Abstract: The objective was to evaluate the risk of seasonal fire at the unfielded and the forest for different climate scenarios. The place of data collection and study was in the Águas Mornas City, State of Santa Catarina. The hourly data were obtained from July 2017 to February 2018, covering the winter, spring and summer seasons. The fire risk was determined through the Setzer Index and Monte Alegre Formula. It was observed the propensity of fires in relation to the future scenarios by the increase of the temperature and the difference between environments. The unfielded area presented higher occurrence of fire in relation to the forest. In climate scenarios there is an increase in 'medium', 'high' and 'very high or critical' risk and a decrease in 'zero or minimum' and 'small or low' risk.

Keywords: Forest fire. Setzer Index. Monte Alegre Formula.

\section{RIESGO DE INCENDIO ESTACIONAL EN ÁREA RASGADA Y BOSQUE POR DIFERENTES ESCENARIOS CLIMÁTICOS EN EL MUNICIPIO DE ÁGUAS MORNAS}

Resumen: El objetivo era evaluar el riesgo de incendio estacional en áreas deforestadas y bosques para diferentes escenarios climáticos. El lugar de recolección de datos se encontraba en el municipio de Águas Mornas, Estado de Santa Catarina. Los datos de tiempo se recopilaron entre julio de 2017 y febrero de 2018, cubriendo las temporadas de invierno, la primavera y verano. El riesgo de incendio fue determinado por el Índice Setzer y la Fórmula Monte Alegre. Se observó la propensión de los incendios en relación con escenarios futuros, precisamente por el aumento de la temperatura. El área deforestada presentaba una mayor ocurrencia

\footnotetext{
${ }^{1}$ Universidade Federal de Santa Catarina (UFSC), Florianópolis, Brasil, betaraspini@hotmail.com, https://orcid.org/0000-0002-9433-7119

2 Universidade Federal de Santa Catarina (UFSC), Departamento de Engenharia Rural, Florianópolis, Brasil, rbminuzzi@hotmail.com, https:// orcid.org/0000-0001-7148-7707
} 
de fuego en relación con el bosque. En los escenarios climáticos hay un aumento en el riesgo 'medio', 'alto' y 'muy alto o crítico' y una disminución en el riesgo 'cero o mínimo' y 'pequeño o bajo'.

Palabras clave: Incendio forestal. Índice de Setzer. Fórmula Monte Alegre.

\section{Introdução}

Os incêndios podem ser provocados tanto por humanos quanto de forma natural por combustão espontânea. Nas florestas é um dos problemas ambientais a serem enfrentados, pois causa perdas econômicas, com impacto na degradação do ecossistema. A vegetação é completamente comprometida nos incêndios, a biodiversidade do local pode ser perdida, ocorrendo a eliminação da cobertura vegetal e dos microrganismos (BERNARDY et al., 2011) e queima da matéria orgânica. As árvores removidas no incêndio deixam a floresta mais vulnerável implicando em uma maior radiação e consequente aumento na temperatura do ar e na suscetibilidade a incêndios futuros (MÉLO, 2009).

Os incêndios agravam o desmatamento, podendo modificar até mesmo o clima em diferentes escalas do espaço. Aos eventuais aumentos de incêndio previstos para o futuro, resultariam em impactos ambientais, sociais e econômicos (CARVALHO et al., 2010). Weatherly e Rosenbaum (2017) especificaram que para várias regiões dos Estados Unidos, com cenário de aumento nos incêndios, os impactos podem ser considerados como severos, com impactos esperados no planejamento militar, saúde, segurança pública e gestão de recursos naturais.

No Brasil, os incêndios são responsáveis por cerca de $75 \%$ das emissões de $\mathrm{CO}_{2}$ para a atmosfera, ratificando como a principal fonte emissora (IBGE, 2015), sendo motivo para preocupação diante das projeções apresentadas nos cenários climáticos futuro.

As projeções apresentadas pelo Painel Brasileiro de Mudanças Climáticas (2014), afirmam que até 2100 poderá ocorrer um aumento de $2,5 \stackrel{\circ}{ } \mathrm{C}$ até $6 \stackrel{\circ}{\mathrm{C}}$ em várias regiões do país. Essa pesquisa foi realizada para diferentes biomas, como a Amazônia, Caatinga, Cerrado, Pampa, Pantanal e Mata Atlântica. A Amazônia é mais preocupante, justamente pelo aumento do desmatamento do local, conforme propõem Cook e Vizy (2008) para o final do século 21, uma redução de aproximadamente $70 \%$ da floresta amazônica. Com isso, a mudança simultânea do clima e da vegetação, tornariam as condições mais propícias para os incêndios. Com uso do Modelo de Circulação Geral Acoplado Oceano-Atmosfera em condições climáticas atuais e futuras, Melo et al. (2008) recorreram aos índices de Setzer e de 
Haines para mostrarem que pode-se esperar aumento no risco de incêndios de grande porte, principalmente na Amazônia. Diante das projeções de aumento da temperatura com diminuição da chuva para Portugal, Carvalho et al. (2010) apontam aumento nas ocorrências de incêndio de $279 \%$ para a segunda metade do século 21, em 12 localidades do país.

Diante da preocupação dos riscos de incêndio em cenários futuros, o objetivo desse estudo foi avaliar o risco de incêndio sazonal numa área descampada e de floresta nativa, para diferentes cenários climáticos futuros.

\section{Material e métodos}

Os dados horários de temperatura do ar e umidade relativa do ar das $13 \mathrm{~h}$ e das $15 \mathrm{~h}$ foram obtidos na localidade de Rio do Cedro, pertencente ao município de

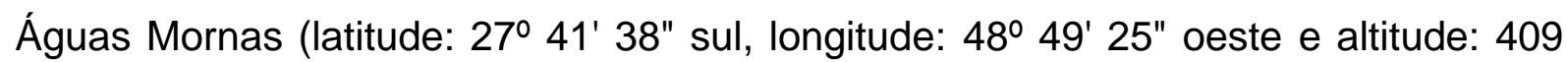
metros), no estado de Santa Catarina. $\mathrm{Na}$ região predomina os terrenos montanhosos, com pequenos planaltos ao longo dos rios. O clima da região é classificado como Cfa (subtropical úmido), com precipitação abundante e distribuída durante o ano. De acordo com Köppen (1936), a temperatura e pluviosidade média anual são de $19,8^{\circ} \mathrm{C}$ e $1531 \mathrm{~mm}$, respectivamente. Julho é considerado o mês mais seco e frio, com $15,6{ }^{\circ} \mathrm{C}$ e $76 \mathrm{~mm}$, ao contrário de janeiro apresentando maior precipitação $(221 \mathrm{~mm})$ e temperatura do $\operatorname{ar}\left(24,2^{\circ} \mathrm{C}\right)$ (ALVARES et al., 2013).

Os termohigrômetros com datalogger foram instalados a 2 metros de altura, e com 270 metros de distância entre si, numa área descampada de aproximadamente $0,01175 \mathrm{~km}^{2}$, circundada por uma floresta nativa ombrófila, com área aproximada de 2,5 km² e de grande densidade de árvores (3 a 4 árvores por $\mathrm{m}^{2}$, com diâmetro altura do peito em média de $5,3 \mathrm{~cm}$, no entorno dos instrumentos). A precipitação horária foi obtida na estação meteorológica pertencente ao Instituto Nacional de Meteorologia (INMET), localizada no município vizinho de Rancho Queimado. A coleta de dados foi realizada nos períodos de 09/07/2017 a 04/08/2017, de 05/11/2017 a 08/12/2017 e de 17/12/2017 a 16/02/2018, representando o inverno, primavera e verão, respectivamente.

O risco de incêndio foi determinado com o uso da Fórmula de Monte Alegre (FMA) e do índice de Setzer (IS).

A FMA foi desenvolvida por Soares (1972). Esta fórmula é acumulativa e tem como única variável a umidade relativa do ar (UR), medida as 13 h (Equação 1). 
$F M A=f . \sum \frac{100}{U R}$

Em que: $f$ = fator de correção, que varia de acordo com a precipitação (Quadro 01).

Os dados da precipitação, utilizados pela FMA foram calculados pelo acumulo das $13 \mathrm{~h}$ às $13 \mathrm{~h}$ local.

\begin{tabular}{cc} 
Quadro 01 - Fator de correção para a FMA. \\
\hline Chuva (mm) & $f$ \\
\hline$<2,40$ & 1,0 \\
2,5 a 4,9 & 0,7 \\
5,0 a 9,9 & 0,4 \\
10,0 a 12,9 & 0,2 \\
$>13,0$ & 0
\end{tabular}

Em que: $f=$ fator de correção.

Após, feitos os cálculos, os resultados são conferidos aos graus de riscos (Quadro 02), conforme cada valor.

Quadro 02 - Grau de risco de incêndio conforme FMA.

Grau de risco FMA acumulada

\begin{tabular}{lc}
\hline Nulo & $\leq 1,0$ \\
Pequeno & 1,1 a 3,0 \\
Médio & 3,1 a 8,0 \\
Alto & 8,1 a 20 \\
Muito alto & $\geq 20$
\end{tabular}

O Índice de Setzer (IS) foi desenvolvido internamente no CPTEC (Centro de Previsão de Tempo e Estudos Climáticos) do Instituto Nacional de Pesquisas Espaciais, com base na análise de diversas queimadas nos principais biomas do Brasil em função das condições e históricos meteorológicos na área de cada evento (SETZER et al., 2002). Seu princípio é que quanto mais dias sem chuva, maior o risco de queimada da vegetação; adicionalmente, são incluídos no cálculo o tipo e o ciclo natural de desfolhamento da vegetação, temperatura máxima e umidade relativa mínima do ar, assim como a presença de fogo na região de interesse. 
- Cálculo dos Fatores de Precipitação (FP): determina o valor de precipitação para o local de estudo em milímetros $(\mathrm{mm})$, acumulada para onze períodos imediatamente anteriores, de $1 ; 2 ; 3 ; 4 ; 5 ; 6$ a 10; 11 a 15; 16 a 30; 31 a 60; 61 a 90 e 91 a 120 dias.

Após isso, calcula-se cada um dos onze períodos a partir de uma função exponencial, de acordo com Equações 2 a 12:

$$
\begin{aligned}
& \mathrm{FP}_{1}=\exp (-0,14 * \text { Prec }) \\
& \mathrm{FP}_{2}=\exp (-0,07 * \text { Prec }) \\
& \mathrm{FP}_{3}=\exp (-0,04 * \text { Prec }) \\
& \mathrm{FP}_{4}=\exp (-0,03 * \text { Prec }) \\
& \mathrm{FP}_{5}=\exp (-0,02 * \text { Prec }) \\
& \mathrm{FP}_{6 \text { a } 10}=\exp (-0,01 * \text { Prec }) \\
& \mathrm{FP}_{11 \text { a } 15}=\exp (-0,008 * \text { Prec }) \\
& \mathrm{FP}_{16 \text { a } 30}=\exp (-0,004 * \text { Prec }) \\
& \mathrm{FP}_{31 \text { a } 60}=\exp (-0,002 * \text { Prec }) \\
& \mathrm{FP}_{61 \text { a } 90}=\exp (-0,001 * \text { Prec }) \\
& \mathrm{FP}_{91 \text { a } 120}=\exp (-0,0007 * \text { Prec })
\end{aligned}
$$

Em que: Prec = é a precipitação.

Vale ressaltar que os dados de precipitação, aplicados ao IS, foram calculados pelo acúmulo foi das $15 \mathrm{~h}$ às $15 \mathrm{~h}$.

- Cálculo dias de secura (PSE): pela multiplicação dos FP, conforme a Equação 13:

$$
\mathrm{PSE}=105 * \mathrm{FP}_{1} * \ldots \mathrm{FP}_{91 \text { a } 120}
$$

Em que: FP = são os fatores de precipitação.

- Risco de incêndio Básico (RB): determina esse cálculo através de uma variável dependendo do tipo de vegetação (Quadro 03), por meio da Equação 14:

$$
\mathrm{RB}=\frac{0,9[1+\operatorname{sen}(\mathrm{A} * \mathrm{PSE})]}{2}
$$


Em que: $A$ = constante de risco de incêndio em função do tipo de vegetação; $\mathrm{PSE}=$ são os dias de secura.

Quadro 03 - Constante de risco de incêndio básico $(R B)$ em função do tipo de vegetação.

\begin{tabular}{ccccccc}
$\begin{array}{c}\text { Classe de } \\
\text { Vegetação }\end{array}$ & 1 & 2 & 3 & 4 & 5 \\
\hline $\begin{array}{c}\text { Tipo de } \\
\text { Vegetação }\end{array}$ & $\begin{array}{c}\text { Ombrófila } \\
\text { Densa }\end{array}$ & $\begin{array}{c}\text { Ombrófila } \\
\text { Aberta }\end{array}$ & $\begin{array}{c}\text { Contato+ } \\
\text { Campinarama }\end{array}$ & $\begin{array}{c}\text { Estacional+ } \\
\text { Decídua+ } \\
\text { Semi-Decídua }\end{array}$ & Fão \\
\hline $\begin{array}{c}\text { Constante } \\
\text { "A" }\end{array}$ & 1,715 & 2 & 2,4 & 3 & 4,7 \\
& & & & & & \\
\end{tabular}

Para os cálculos na área descampada, a constante utilizada foi 4,7 , enquanto na área de floresta, como foram perto do parque estadual da serra do tabuleiro, a constante utilizada foi 1,715, conforme a classificação da vegetação local.

- Risco de incêndio para umidade relativa do ar (RU): Usam se dados observados no horário de ocorrência de menor valor da umidade relativa.

$$
\mathrm{RU}=\mathrm{RB}\left(0,006 * \mathrm{UR}_{\min }+1,3\right)
$$

Em que: $R B$ = é o risco de incêndio básico; $U R$ mín = é a umidade relativa mínima diária do ar.

- Risco de incêndio para a temperatura do ar (RT): Usam se dados observados no horário de ocorrência máxima da temperatura.

$$
\begin{aligned}
& \mathrm{RT}=\mathrm{RU}\left(0,02 * \mathrm{~T}_{\text {máx }}+0,4\right) \\
& \text { Risco de Incêndio Finnal }(\mathrm{RF})=\mathrm{RT}=\mathrm{IS}
\end{aligned}
$$

Em que: $\mathrm{RU}=0$ risco de incêndio para umidade relativa do ar; $T_{\text {máx }}=$ é a temperatura máxima do ar; $\mathrm{RT}=$ é o risco de incêndio para a temperatura do ar.

Realizado os cálculos do IS, têm-se o risco de incêndio final atribuído a diferentes categorias para cada valor (Quadro 04).

Quadro 04 - Classes de risco de incêndio, de acordo com o Índice de Setzer (IS). Nível de risco Índice de Setzer

$$
\text { Mínimo } \quad 0,00 \text { a } 0,15
$$




$\begin{array}{cc}\text { Baixo } & 0,15 \text { a } 0,40 \\ \text { Médio } & 0,40 \text { a } 0,70 \\ \text { Alto } & 0,70 \text { a } 0,90 \\ \text { Crítico } & >0,90\end{array}$

Aos dados meteorológicos registrados durante o experimento em ambos os ambientes, os riscos de incêndio foram recalculados, considerando as projeções feitas pelo Painel Intergovernamental sobre Mudança Climática (do inglês, IPCC) de 2013 para a região sul do Brasil, baseadas nos valores do percentil 25\% e 75\% para os cenários RCP4.5 e RCP8.5 (RCP, do inglês, Representative Concentration Pathway), a curto prazo (2016-2035) e a médio prazo (2046-2065). O primeiro cenário considera que serão tomadas atitudes para reduzir a emissão de $\mathrm{CO}_{2}$, ao contrário do RCP8.5, o qual não serão tomadas medidas para evitar.

Os desvios trimestrais de temperatura e semestrais de precipitação projetados para o sul do Brasil são apresentados no Quadro 05 e 06. Já a umidade relativa do ar foi estimada a sua variação com o uso de uma equação de regressão, tendo a temperatura do ar (T) como variável preditora. O IS utilizando a temperatura máxima, e a FMA a temperatura das $13 \mathrm{~h}$. Desta forma, foram utilizadas quatro equações, uma para cada ambiente e índice.

Para os cálculos da umidade relativa do ar (UR) do IS, no ambiente a floresta e campo, utilizou-se as Equações 18 e 19, respectivamente:

$$
\begin{aligned}
& \mathrm{UR}=(-3,1718 * \mathrm{~T})+137,36 \\
& \mathrm{UR}=(-2,1633 * \mathrm{~T})+100,14
\end{aligned}
$$

Agora para a FMA, também no ambiente a floresta e campo, utilizou-se as Equações 20 e 21, respectivamente:

$$
\begin{aligned}
& \mathrm{UR}=(-3,1586 * \mathrm{~T})+137,36 \\
& \mathrm{UR}=(-2,0382 * \mathrm{~T})+102,86
\end{aligned}
$$


Quadro 05 - Desvios trimestrais de temperatura média do ar $\left({ }^{\circ} \mathrm{C}\right)$ baseados nos percentis $25 \%$ e $75 \%$ projetados para a região sul do Brasil, pelo cenário RCP4.5 e RCP8.5 do IPCC para os períodos 2016-2035 e 2046-2065.

\begin{tabular}{lllllll}
\hline RCP4.5 & \multicolumn{2}{c}{ dez-fev } & \multicolumn{2}{c}{ jun-ago } & \multicolumn{2}{c}{ set-nov } \\
\hline Período & $25 \%$ & $75 \%$ & $25 \%$ & $75 \%$ & $25 \%$ & $75 \%$ \\
\hline $2016-2035$ & 0,5 & 1,0 & 0,7 & 1,2 & 0,5 & 1,0 \\
\hline $2046-2065$ & 1,0 & 1,7 & 1,0 & 2,0 & 1,0 & 2,0 \\
\hline RCP8.5 & & & & & & \\
\hline $2016-2035$ & 1,3 & 1,7 & 1,3 & 1,7 & 1,3 & 1,7 \\
\hline $2046-2065$ & 1,7 & 3,5 & 1,7 & 2,5 & 1,7 & 2,5
\end{tabular}

Fonte: Adaptado de IPCC (2013)

Quadro 06 - Desvios semestrais de precipitação (\%) baseadas nos percentis 25\% e 75\% projetados para a região sul do Brasil, pelo cenário RCP4.5 e RCP8.5 do IPCC para os períodos 2016-2035 e 2046-2065.

RCP4.5 RCP8.5

\begin{tabular}{ccccccccc}
\hline & \multicolumn{2}{c}{ out-mar } & \multicolumn{2}{c}{ abr-set } & \multicolumn{2}{c}{ out-mar } & \multicolumn{2}{c}{ abr-set } \\
\hline Período & $25 \%$ & $75 \%$ & $25 \%$ & $75 \%$ & $25 \%$ & $75 \%$ & $25 \%$ & $75 \%$ \\
\hline $2016-2035$ & -5 & +5 & -5 & +5 & -5 & +5 & -5 & +5 \\
\hline $2046-2065$ & -5 & +15 & -5 & +15 & +5 & +15 & -5 & +15
\end{tabular}

Fonte: Adaptado de IPCC (2013)

\section{Resultados e discussão}

Pela FMA, os maiores riscos de incêndio foram observados na área descampada, durante a primavera e, principalmente, no inverno (Gráfico 01a). Na estação mais fria do ano, os dois maiores percentuais de dias com risco de incêndio a campo, foram nas classes 'muito alto' (25,9\%) e 'alto' (37\%), enquanto na primavera, para ambos os ambientes, dias com 'médio' e 'alto' risco de incêndio foram predominantes e com número de ocorrências quase iguais. Esses resultados são coerentes ao encontrado por Torres et al. (2016), que realizaram um levantamento de incêndios ocorridos nas unidades de conservação do Brasil. Encontraram que os meses com maior ocorrência de incêndios foram agosto, setembro e outubro. Porém, chamam a atenção que em função da diversidade climática de cada região as variáveis que favorecem os incêndios variam de um local para outro. 
Gráfico 01 - Porcentagem de dias (\%) associados à classe de risco de incêndio conforme o FMA (1a) e IS (1b), equivalentes a cada estação do ano, em área descampada e na floresta.
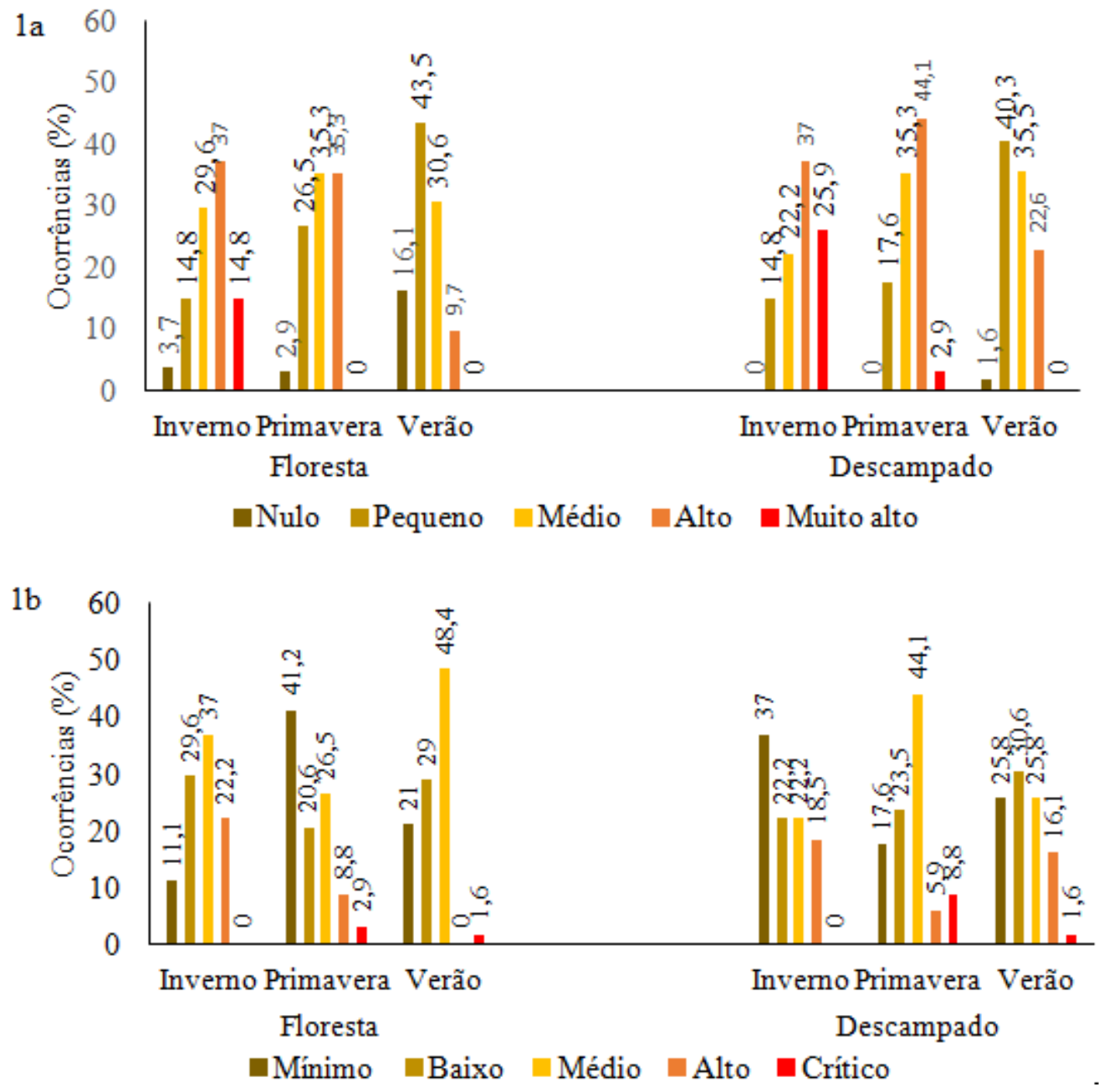

Fonte: Elaborado pelos autores.

Com o IS, as maiores ocorrências diárias com riscos 'alto' e 'crítico' foram menores (Figura 1b) do que as obervadas com o uso do FMA. Um exemplo que ilustra fielmente este comparativo foi durante o inverno, em que, na floresta pela FMA, houve 37 e 14,8\% e pelo IS, 22,2 e $0 \%$ das duas classes de maiores riscos de incêndio. No ambiente descampado, os valores para as referidas classes de risco de incêndio foram de 37 e 25,9\% pela FMA e de 18,5 e $0 \%$ pelo IS. Assunção et al. (2013), avaliaram os períodos mais propícios a ocorrência de incêndio na região do Vale do Gurguéia no estado do Piauí no ano de 2007 a 2012 através da utilização da FMA. O inverno também apresentou as maiores chances de ocorrência incêndio, consequentemente nos meses em que a umidade relativa do ar mostrou-se baixa.

Teixeira et al. (2017) detalharam os períodos de maiores focos ao avaliarem a relação dos incêndios e as chuvas entre os anos de 1999 a 2016, em Santa Catarina. Os meses de julho e agosto apresentaram um aumento nos focos de calor 
com decréscimo no mês de setembro. Somado a uma maior probabilidade de dias sem chuva, além de uma menor precipitação média mensal, esses meses foram mais propícios à ocorrência de incêndios.

No comparativo entre os ambientes, os riscos de incêndios foram maiores no ambiente descampado do que na floresta, usufruindo dos valores obtidos pelo IS, já que envolve maior número de variáveis meteorológicas e estas diferenciam-se entre os ambientes. Adiciona-se a isto, a vegetação das florestas que ocasiona um aumento na taxa de evapotranspiração e redução na passagem de raios solares (MARTINI; BIONDI, 2015), mantendo a umidade e reduzindo a temperatura (ABREU, 2008). Diferente do que ocorre em ambiente descampado, com menor taxa de evapotranspiração e maior incidência de raios solares, resulta numa diminuição na umidade e um aumento na temperatura do ar, proporcionando uma alta taxa de matérias inflamáveis (WORLD METEOROLOGICAL ORGANIZATION, 2012).

Aos registros obtidos durante o experimento foram ajustados e determinados os riscos de incêndio considerando os desvios projetados pelos cenários futuros. A Tabela 01 mostra o desvio percentual de ocorrências diárias de risco de incêndio usando a FMA para os cenários RCP4.5 e RCP8.5 à curto prazo. No comparativo entre os diferentes cenários climáticos, mas em mesmo ambiente, praticamente ocorreu pouca diferença expressiva no número de ocorrências de riscos de incêndio. 
Tabela 01 - Desvios percentuais no número de dias nas diferentes classes de risco de incêndio sazonal conforme a FMA, em ambiente descampado e na floresta, para os cenários RCP4.5 e RCP8.5 baseadas nos valores do percentil 25\% e $75 \%$ a curto prazo (2016-2035). Grau de

Risco

Nulo

Pequeno

Médio

Alto

Muito alto

Floresta

\begin{tabular}{ccccccccccc}
\hline RCP4.5 & $25 \%$ & $75 \%$ & $25 \%$ & $75 \%$ & $25 \%$ & $75 \%$ & $25 \%$ & $75 \%$ & $25 \%$ & $75 \%$ \\
\hline Inverno & $-3,7$ & $-3,7$ & 0 & $+3,7$ & 0 & $-3,7$ & $+3,7$ & $+3,7$ & 0 & 0 \\
\hline Primavera & $-2,9$ & $-2,9$ & -3 & $-5,9$ & $+2,9$ & $+5,9$ & $+2,9$ & $+5,9$ & 0 & 0 \\
\hline Verão & $-16,1$ & $-16,1$ & -8 & $-6,4$ & $+12,9$ & $+11,3$ & $+11,2$ & $+11,2$ & 0 & 0 \\
\hline
\end{tabular}

RCP8.5

\begin{tabular}{cccccccccccc}
\hline Inverno & $-3,7$ & $-3,7$ & 0 & $+3,7$ & 0 & $-3,7$ & $+3,7$ & $+3,7$ & 0 & 0 \\
\hline Primavera & $-2,9$ & $-2,9$ & $-5,9$ & $-5,9$ & $+5,9$ & $+5,9$ & $+2,9$ & $+2,9$ & 0 & 0 \\
\hline Verão & $-16,1$ & $-16,1$ & $-11,2$ & -8 & $+16,2$ & $+12,9$ & $+11,2$ & $+11,2$ & 0 & 0 \\
\hline
\end{tabular}

Grau de

Risco

Descampado

\begin{tabular}{cccccccc|cccc}
\hline RCP4.5 & \multicolumn{10}{c}{0} \\
\hline Inverno & 0 & 0 & 0 & $+3,7$ & 0 & 0 & $+3,7$ & $+3,7$ & $-3,7$ & $-7,4$ \\
\hline Primavera & 0 & 0 & $-2,9$ & $-2,9$ & $+5,9$ & $+2,9$ & $-2,9$ & 0 & 0 & 0 \\
\hline Verão & $-1,6$ & $-1,6$ & $-16,1$ & $-12,9$ & $+14,5$ & $+9,7$ & 0 & $+1,6$ & $+3,2$ & $+3,2$ \\
\hline RCP8.5 & 0 & 0 & $+3,7$ & 0 & $+3,7$ & 0 & $+3,7$ & $+3,7$ & $-3,7$ & $-3,7$ \\
\hline Inverno & 0 & 0 & $-2,9$ & $-2,9$ & $+2,9$ & $+2,9$ & 0 & $-2,9$ & 0 & +3 \\
\hline Primavera & 0 & 0 & & & & & \\
\hline Verão & $-1,6$ & $-1,6$ & $-17,7$ & $-14,5$ & $+12,9$ & $+9,7$ & $+5,2$ & $+5,2$ & $+3,2$ & $+3,2$ \\
\hline
\end{tabular}

No comparativo entre as ocorrências observadas e as previstas diante de ambos os cenários, haverá um aumento unânime no risco 'alto', e uma diminuição no risco 'nulo' de incêndio para a floresta e tendências diversificadas no 'pequeno' e 'médio' risco. Porém na área descampada, observa-se uma tendência quase unânime na diferença entre os resultados, até mesmo entres os percentis $25 \%$ e 75\%. Na estação da primavera ocorreu uma diminuição de 2,9\% no risco 'alto', porém um aumento de 3\% no risco 'muito alto' de fogo no cenário RCP8.5. Na contrapartida, chama atenção a redução do risco 'muito alto' de incêndio na área descampada, durante o inverno. Essa característica deve-se a alteração da umidade 
relativa do ar, que por ter sido estimada pela equação de regressão, alguns resultados foram maiores, mesmo com os cenários de aumento da temperatura do ar. No verão, em ambos os ambientes e cenários climáticos, há tendência de diminuir o 'nulo' e 'pequeno' risco de incêndio, mas aumentar o restante, enquanto, durante a primavera, as tendências são diversificadas.

Nas projeções a médio prazo, a diferença dos desvios é pequena em relação ao observado a curto prazo, principalmente no ambiente a floresta, porém os 'médios', 'alto' e 'muito alto' risco aumentaram neste ambiente principalmente no cenário RCP8.5, durante o verão (Tabela 02).

Tabela 02 - Desvios percentuais no número de dias nas diferentes classes de risco de incêndio sazonal conforme a FMA, em ambiente descampado e na floresta, para os cenários RCP4.5 e RCP8.5 baseadas nos valores do percentil $25 \%$ e $75 \%$ a médio prazo (20462065).

\begin{tabular}{|c|c|c|c|c|c|c|c|c|c|c|}
\hline Grau de Risco & \multicolumn{2}{|c|}{ Nulo } & \multicolumn{2}{|c|}{ Pequeno } & \multicolumn{2}{|c|}{ Médio } & \multicolumn{2}{|c|}{ Alto } & \multicolumn{2}{|c|}{ Muito alto } \\
\hline RCP4.5 & $25 \%$ & $75 \%$ & $25 \%$ & $75 \%$ & $25 \%$ & $75 \%$ & $25 \%$ & $75 \%$ & $25 \%$ & $75 \%$ \\
\hline Inverno & $-3,7$ & $-3,7$ & 0 & $+3,7$ & 0 & $-3,7$ & $+3,7$ & $+3,7$ & 0 & 0 \\
\hline Primavera & $-2,9$ & $-2,9$ & $-5,9$ & $-5,8$ & $+5,9$ & $-8,8$ & $+2,9$ & $+5,9$ & 0 & 0 \\
\hline Verão & $-16,1$ & $-16,1$ & -8 & $-6,4$ & $+12,9$ & $+11,3$ & $+11,2$ & $+11,2$ & 0 & 0 \\
\hline \multicolumn{11}{|l|}{ RCP8.5 } \\
\hline Inverno & $-3,7$ & $-3,7$ & 0 & 3,7 & 0 & $-3,7$ & $+3,7$ & $+3,7$ & 0 & 0 \\
\hline Primavera & $-2,9$ & $-2,9$ & $-5,9$ & 0 & $+8,8$ & -3 & $+2,9$ & $+5,9$ & 0 & 0 \\
\hline Verão & $-16,1$ & $-16,1$ & $-9,6$ & $-12,9$ & $+14,6$ & $+14,6$ & $+11,2$ & $+12,9$ & 0 & $+1,6$ \\
\hline \multicolumn{11}{|l|}{ Grau de Risco } \\
\hline \multicolumn{11}{|l|}{ Descampado } \\
\hline \multicolumn{11}{|l|}{ RCP4.5 } \\
\hline Inverno & 0 & 0 & 0 & 0 & 0 & 0 & $+3,7$ & $+3,7$ & $-3,7$ & $-3,7$ \\
\hline Primavera & 0 & 0 & $-5,8$ & 0 & 0 & 0 & 0 & $-2,9$ & 0 & +3 \\
\hline Verão & $-1,6$ & $-1,6$ & $-16,1$ & $-14,5$ & $+11,3$ & $+9,7$ & $+3,2$ & $+3,2$ & $+3,2$ & $+3,2$ \\
\hline \multicolumn{11}{|l|}{$\mathrm{RCP8,5}$} \\
\hline Inverno & 0 & 0 & $-3,7$ & 0 & $+3,7$ & $-3,7$ & 0 & 7,4 & 0 & $-3,7$ \\
\hline Primavera & 0 & 0 & $-5,8$ & 0 & $+2,9$ & 0 & $-2,9$ & $-2,9$ & +3 & +3 \\
\hline Verão & $-1,6$ & $-1,6$ & $-14,5$ & $-19,4$ & $+9,7$ & $+12,9$ & $+3,2$ & $+3,2$ & $+3,2$ & $+4,8$ \\
\hline
\end{tabular}

Já a campo, as tendências foram bem diversificadas, inclusive comparando os valores entre os percentis de determinada classe. Pode-se fazer algumas 
observações importantes, como a ausência de mudança nos riscos para o inverno nas classes 'nulo' até a 'médio', sendo essa característica presente também na primavera, principalmente no cenário RCP4.5. O inverno teve um aumento no risco 'alto', em contrapartida continuou com diminuição nos riscos 'muito alto', porém com uma diferença menor. No verão, houve uma diminuição no risco 'nulo' e 'pequeno' e aumento nas classes 'média', 'alto' e 'muito alto' em ambos os cenários. Na primavera, ocorreu o contrário, o risco 'alto' teve diminuição, porém a classe 'muito alta' obteve um aumento.

Nos cálculos utilizados pelo IS (Tabela 03) percebe-se a diferença entre a FMA (Tabelas 01 e 02), ocorre um aumento maior nos riscos 'críticos' em todas as estações do ano analisadas, porém no inverno em ambiente de floresta os riscos 'mínimo' e 'baixo' aumentaram, enquanto o risco 'médio' e ‘alto' diminuíram. Já a campo essa característica foi possível na primavera o risco 'mínimo' aumentou, porém com uma diferença, a classe 'baixa' diminuiu e a classe 'alta' aumentou.

Tabela 03 - Desvios percentuais no número de dias nas diferentes classes de risco de incêndio sazonal conforme o IS, em ambiente descampado e na floresta, para os cenários RCP4.5 e RCP8.5 baseadas nos valores do percentil 25\% e 75\% a curto prazo (2016-2035).

Grau de Risco

$\begin{array}{llll} & \text { Mínimo } & \text { Baixo } & \text { Médio }\end{array}$

Floresta

$25 \% \quad 75 \% \quad 25 \% \quad 75 \% \quad 25 \% \quad 75 \% \quad 25 \% \quad 75 \% \quad 25 \% \quad 75 \%$

\begin{tabular}{cccccccccccc}
\hline Inverno & $+40,7$ & $+29,6$ & $-7,4$ & $+3,7$ & $-11,1$ & $-14,8$ & $-22,2$ & $-18,5$ & 0 & 0 \\
\hline Primavera & $-20,6$ & $-17,7$ & 0 & -3 & $+14,2$ & $+17,6$ & $+8,8$ & $+6,2$ & $+2,9$ & $+2,9$ \\
\hline Verão & $-3,3$ & $-1,7$ & $-6,4$ & $-8,1$ & $-3,2$ & $-6,5$ & $+14,5$ & $+17,7$ & $+1,6$ & $+1,6$ \\
\hline RCP8.5 & & & & & & & & & & \\
\hline Inverno & +37 & $+29,6$ & $-7,4$ & 0 & $-11,1$ & $-14,8$ & $-22,2$ & $-18,5$ & 0 & 0 \\
\hline Primavera & $-20,6$ & $-17,7$ & 0 & -3 & $+14,2$ & $+17,6$ & $+8,8$ & $+5,9$ & $+2,9$ & $+2,9$ \\
\hline Verão & $-3,3$ & $-3,3$ & $-8,1$ & $-9,7$ & $-1,6$ & $-4,9$ & $+14,5$ & $+17,7$ & $+1,6$ & 0 \\
\hline
\end{tabular}

Grau de Risco

Descampado

\begin{tabular}{ccccccccccccc}
\hline RCP4.5 & $-22,2$ & $-3,7$ & 0 & $+3,7$ & $+14,8$ & $-7,4$ & $+7,4$ & 0 & 0 & $+3,7$ \\
\hline Inverno & $+11,8$ & $+11,8$ & $-2,9$ & - & $-11,8$ & $-17,6$ & 0 & $+11,7$ & +3 & $+5,9$ \\
\hline Primavera & & & & 11,7 & & & & & & \\
& $-1,6$ & $-3,2$ & $-20,9$ & - & $+3,2$ & $+8,1$ & $+3,2$ & $+3,2$ & $+16,1$ & $+11,3$ \\
\hline Verão & & & & 19,3 & & & & & \\
\hline
\end{tabular}


RCP8.5

\begin{tabular}{|c|c|c|c|c|c|c|c|c|c|c|}
\hline Inverno & $-22,2$ & 0 & 0 & 0 & $+14,8$ & $-3,7$ & 0 & 0 & $+7,4$ & $+3,7$ \\
\hline Primavera & $+11,8$ & $+11,8$ & $-2,9$ & 11,7 & $-14,7$ & $-17,6$ & $+2,9$ & $+11,8$ & +3 & $+8,8$ \\
\hline Verão & $-1,6$ & $-4,9$ & 20,9 & $\begin{array}{c}- \\
19,3\end{array}$ & $+1,6$ & $+4,8$ & $+1,6$ & $+8,1$ & $+19,3$ & $+11,3$ \\
\hline
\end{tabular}

Em suma, se o risco 'mínimo' e 'baixo' aumentou, e o 'médio' e 'alto' diminuíram, isto foge um pouco a lógica, pois com o aumento da temperatura prevista, que está associada a uma menor umidade relativa, tornaria um ambiente mais seco e, assim, com maior risco para incêndio. Até mesmo realizando uma pesquisa com outros trabalhos que utilizaram o IS, não foi possível encontrar esse resultado, porém as equações utilizadas dão apenas estimativas, podendo ocorrer divergências entre valores.

O verão continuou apresentando uma diminuição nas chances menores de incêndio, e um aumento nos riscos maiores de ocorrência de fogo, em ambos cenários e ambientes.

Nas projeções a médio prazo (Tabela 04), durante o inverno o risco mínimo e baixo diminuiu, enquanto as demais classes aumentaram. Já na estação mais quente do ano, apenas o risco 'alto' e 'crítico' aumentaram.

Tabela 04 - Desvios percentuais no número de dias nas diferentes classes de risco de incêndio sazonal conforme o IS, em ambiente descampado e na floresta, para os cenários RCP 4.5 e RCP8.5 baseadas nos valores do percentil $25 \%$ e $75 \%$ a médio prazo (20462065).

Grau de

Risco Mínimo Baixo Médio Alto Crítico

Floresta

\begin{tabular}{ccccccccccc}
\hline RCP4.5 & $25 \%$ & $75 \%$ & $25 \%$ & $75 \%$ & $25 \%$ & $75 \%$ & $25 \%$ & $75 \%$ & $25 \%$ & $75 \%$ \\
\hline Inverno & $+33,4$ & $+29,6$ & $-7,4$ & $+7,4$ & $-11,1$ & $-18,5$ & $-22,2$ & $-18,5$ & 0 & 0 \\
\hline Primavera & $-20,6$ & $-14,7$ & 0 & -3 & $+14,7$ & $+5,8$ & $+8,8$ & $+11,8$ & $+2,9$ & 0 \\
\hline Verão & $-3,3$ & $-8,1$ & $-8,1$ & $-8,1$ & $-1,6$ & $-14,5$ & $+14,5$ & $+27,4$ & $-1,6$ & $+6,4$ \\
\hline RCP8.5 & & & & & & & & & \\
\hline Inverno & +37 & $+25,9$ & $-7,4$ & $+11,1$ & $-7,4$ & $-22,2$ & $-22,2$ & $-14,8$ & 0 & 0 \\
\hline Primavera & $-17,7$ & $-14,7$ & -3 & -3 & $+17,6$ & $+2,9$ & +3 & $+14,7$ & 0 & 0 \\
\hline Verão & $-4,9$ & $-8,1$ & $-6,4$ & $-14,5$ & $-6,5$ & $-11,3$ & $+16,1$ & $+22,6$ & $+1,6$ & $+12,9$ \\
\hline
\end{tabular}

Grau de 
Risco

Descampado

\begin{tabular}{cccccc|ccccccc}
\hline RCP4.5 & \multicolumn{10}{c}{0} \\
\hline Inverno & $-22,2$ & $-18,5$ & 0 & $+11,1$ & $-14,8$ & $-11,1$ & $+7,4$ & $+11,1$ & 0 & $+3,7$ \\
\hline Primavera & $+11,8$ & $+11,8$ & $-2,9$ & $-17,6$ & $-14,7$ & $-20,6$ & $+2,9$ & $+14,7$ & +3 & $+11,8$ \\
\hline Verão & $-6,5$ & $-12,9$ & $-20,9$ & $-17,7$ & $+8,1$ & $+11,3$ & $+1,6$ & $+9,7$ & $+17,7$ & $+9,7$ \\
\hline RCP8.5 & & & & & & & & & & \\
\hline Inverno & $-14,8$ & $-18,5$ & $-7,4$ & $+7,4$ & 0 & $-7,4$ & $+7,4$ & $+14,8$ & $+11,1$ & $+3,7$ \\
\hline Primavera & $+14,6$ & $+11,8$ & $-11,7$ & $-17,6$ & $-14,7$ & $-23,5$ & $+23,5$ & $+5,9$ & +3 & $+11,8$ \\
\hline Verão & $-3,2$ & $-12,9$ & $-17,7$ & $-17,7$ & $+4,8$ & $+4,8$ & $+6,5$ & $+12,9$ & $+9,7$ & $+11,3$ \\
\hline
\end{tabular}

$\mathrm{Na}$ área descampada percebe-se um aumento no risco 'alto'. No risco 'crítico' essa característica foi observada na primavera, porém nessa estação o risco 'mínimo' obteve um aumento, em contrapartida o risco 'médio' diminuiu. O verão apresentou um aumento no risco 'médio', 'alto' e 'crítico'.

No contexto geral, percebe-se a diferença entre os resultados ajustados a FMA, em relação aos ajustados ao IS.

Em relação ao risco crítico de incêndios, o IS apresentou valores mais altos, porém ambos os índices tiveram o risco presente em todos as estações. Melo et al. (2008) mostraram que o IS usado em cenários futuros foi extremamente sensível a condição imposta pela vegetação, no sentido que as áreas que tiveram a substituição da floresta por cerrado, apresentaram um maior risco de incêndio.

Os resultados referentes aos cálculos da FMA, não diferem muito no ambiente a floresta, porém na área descampada percebe-se uma pequena diferença. Outro ponto analisado foram os dados referentes ao cenário RCP8.5, houve um pequeno aumento no risco 'muito alto' no verão principalmente no percentil 75\%, em comparação ao cenário RCP4.5.

Dowdy (2018) destacou que há uma clara tendência de aumento nas condições para ocorrência de incêndio durante a primavera e verão no sul da Austrália, indicando um início cada vez mais precoce do "período de incêndio" na região. A essas tendências o pesquisador atribuiu em parte às mudanças climáticas, principalmente na relação com o aumento da temperatura do ar.

Aos resultados relacionados ao IS, há uma diferença maior. Os cenários projetados a médio prazo possuem um aumento significativo no risco 'alto' de 
incidências de fogo, em relação aos de curto prazo, sendo diferente apenas no inverno, o qual obteve uma diminuição nas maiores chances de ocorrer incêndio. A diferença também é perceptível no que se refere aos dois ambientes e dois cenários, onde os valores mais altos de risco de incêndio são maiores a campo e alguns no cenário RCP 8.5. Como esperado, isso se explica, pelo fato que no cenário RCP4.5 considera-se que serão tomadas atitudes para reduzir a emissão de $\mathrm{CO}_{2}$ e os desvios de temperatura e precipitação em relação ao clima atual são menores, ao contrário do RCP8.5, o qual não serão tomadas medidas para evitar as mudanças climáticas, o que vai causar consequentemente um maior aumento de temperatura nesse cenário e chances maiores de incidências de incêndio.

O Painel Brasileiro de Mudanças Climáticas (2014) avaliou o número total de focos de incêndio no ano de 2010 e a profundidade óptica de aerossóis (AOD). 0 número maior de índices de $A O D$ foi em florestas, mesmo sendo a menor área queimada, justamente pelo diferente conteúdo de biomassa queimada. O impacto da queima de biomassa de floresta primária é muito maior do que em outros tipos de vegetação, como cerrado ou em culturas agrícolas, isto é, durante a seca os incêndios florestais constituem a principal fonte de aerossol para a atmosfera do Brasil.

As variabilidades de elementos climáticos se correlacionam entre si, como a precipitação tem influência na umidade relativa do ar e na umidade do material combustível. A interação da umidade do ar e a temperatura do ar tem forte atuação nas características do incêndio e na secagem das matérias inflamáveis, isto é, quanto mais água tiver no material combustível, mais difícil será o início do fogo. Como exemplo, Mbanze et al. (2015) avaliaram as influências meteorológicas na ocorrência de incêndios florestais no distrito de Lichinga, norte de Moçambique. As incidências de fogo foram maiores aonde as taxas de umidade eram menores juntamente com temperaturas maiores.

Para uma análise mais precisa de ocorrência e comportamento de incêndios, também são analisadas a topografia, o vento e a constituição do material combustível. A taxa de propagação de incêndio é muito mais lenta nas descidas, já que o ângulo da chama é geralmente negativo. A topografia também influencia fortemente o vento, conduzindo-o para as direções preferidas conforme a angulação do relevo. Quando a velocidade do vento aumenta, o comportamento do fogo muda drasticamente, alastrando o fogo para outros lugares. Os combustíveis encontrados no ambiente são as plantas, árvores no caso de florestas e gramíneas em campo, 
até as matérias mortas, como folhas e galhos. Nesse caso os combustíveis têm um grande número de combinações de forma, tamanho, quantidade, disposição e espécie, sendo necessário conhecer e determinar a facilidade ou não que um combustível tem em inflamar e queimar e, portanto, influenciar fortemente o comportamento do fogo (WORLD METEOROLOGICAL ORGANIZATION, 2012).

\section{Conclusão}

Nos cenários climáticos futuros há um aumento no risco de incêndio em área descampada e de floresta e em todas as estações do ano analisadas, principalmente, no cenário mais pessimista (RCP8.5) a médio prazo.

\section{REFERÊNCIAS}

ABREU, L. V. de. Avaliação da escala de influência da vegetação no microclima por diferentes espécies arbóreas. 2008. Dissertação (Mestrado em Engenharia Civil) Universidade Estadual de Campinas, Campinas, 2008.

ALVARES, C. A. et al. Köppen's climate classification map for Brazil. Meteorologische Zeitschrift, Stuttgart, v. 22, n. 6, p.711-728, 2013.

ASSUNÇÃO, A. B. D. et al. Utilização da Fórmula de Monte Alegre para identificação de períodos propícios à ocorrência de incêndios na região do vale do Gurgueia. In: CONGRESSO BRASILEIRO DE AGROMETEOROLOGIA, 18. 2013, Belém, PA. Anais [...]. Belém: CBA, 2013. p. 1-6.

BERNARDY, K. et al. Impactos ambientais diante das catástrofes naturais - secas e queimadas. In: SEMINÁRIO INTERINSTITUCIONAL DE ENSINO, PESQUISA E EXTENSÃO, 16., 2011, Cruz Alta. Anais [...]. Cruz Alta: Unicruz, 2011. p. 1-4.

CARVALHO, A. et al. The impact of spatial resolution on area burned and fire occurrence projections in Portugal under climate change. Climatic Change, [s.I.], v. 98, n. 1-2, p.177197, jan. 2010.

COOK, K.; VIZY, E. K. Effects of Twenty-First Century climate change on the Amazon rain forest. Journal of Climate, v. 21, n. 3, p.542-560, 2008.

DOWDY, A. J. Climatological variability of fire weather in Australia. Journal of Applied Meteorology and Climatology, Boston, v. 57, n. 2, p. 221-234, 2018.

INSTITUTO BRASILEIRO DE GEOGRAFIA E ESTATÍSTICA - IBGE. Indicadores de desenvolvimento Sustentável. Rio de Janeiro: IBGE, 2015. 352 p.

INTERGOVERNMENTAL PANEL ON CLIMATE CHANGE - IPCC. Climate change 2013: The Physical Science Basis. Contribution of Working Group I to the Fifth Assessment Report of the Intergovernmental Panel on Climate Change. Genebra: IPCC, 2013.

MARTINI, A.; BIONDI, D. Microclima e conforto térmico de um fragmento de floresta urbana em Curitiba, PR. Floresta e Ambiente, Rio de Janeiro, v. 22, n. 2, p.182-193, 2015. 
MÉLO, A. S. de. Suscetibilidade do ambiente a ocorrência de queimadas sob condições climáticas atuais e de aquecimento global. 2009. Dissertação (Mestrado em Meteorologia Agrícola) - Universidade Federal de Viçosa, Viçosa, 2009.

MELO, A. S. de et al. Índices de risco de fogo de Haines e Setzer em diferentes condições climáticas. Mercator, v. 11, n. 24, p.187-207, 2012.

MBANZE, A. A. et al. Influence of the meteorological conditions on forest fires occurrences in Lichinga District, Northern Mozambique. Floresta, Curitiba, v. 45, n. 3, p. 577-586, mar. 2015.

PAINEL BRASILEIRO DE MUDANÇAS CLIMÁTICAS - PBMC. Base científica das mudanças climáticas: primeiro relatório de avaliação nacional. Rio de Janeiro: PBMC, 2014. 392p.

SETZER, A. et al. O uso de satélites NOAA na detecção de queimadas no Brasil. Climanálise, v. 7, n 8, p. 40-53, 2002.

SOARES, R. V. Índices de perigo de incêndio. Floresta, Curitiba, v. 3, n. 3, p. 19-40, 1972.

TEIXEIRA, N. C. et al. Análise preliminar da relação entre queimadas e chuvas no estado de Santa Catarina. In: SIMPÓSIO BRASILEIRO DE RECURSOS HÍDRICOS, 22., 2017, Florianópolis, SC. Anais [...]. Florianópolis: SBRH, 2017. p. 1-8.

TORRES, F. T. P. et al. Perfil dos incêndios florestais em unidades de conservação brasileiras no período de 2008 a 2012. Floresta, Curitiba, v. 46, n. 4, p. 531-542, ago. 2016.

WEATHERLY, J. W.; ROSENBAUM, M. A. Future projections of heat and fire-risk indices for the contiguous United States. Journal of Applied Meteorology and Climatology, Boston, v. 56, n. 4, p.863-876, 2017.

WORLD METEOROLOGICAL ORGANIZATION - WMO. Weather and climate forecasts for agriculture. [S.I.]: WMO, 2012. 790p.

\section{NOTAS DE AUTOR}

\section{CONTRIBUIÇÃO DE AUTORIA}

Roberta Raspini Januário - Análise de dados e obtenção estatística, Elaboração do manuscrito. Rosandro Boligon Minuzzi - Concepção, Coleta de dados, Revisão e aprovação da versão final.

\section{FINANCIAMENTO}

Não se aplica.

\section{CONSENTIMENTO DE USO DE IMAGEM}

Não se aplica.

\section{APROVAÇÃO DE COMITÊ DE ÉTICA EM PESQUISA}

Não se aplica.

\section{CONFLITO DE INTERESSES}

Não se aplica.

\section{LICENÇA DE USO}

Este artigo está licenciado sob a Licença Creative Commons CC-BY. Com essa licença você pode compartilhar, adaptar, criar para qualquer fim, desde que atribua a autoria da obra.

\section{HISTÓRICO}

